\title{
Thermomechanical Model and Bursting Tests to Evaluate the Risk of Swelling and Bursting of Modified 9Cr-1Mo Steel Steam Generator Tubes during a Sodium-Water Reaction Accident
}

\author{
C. Bertrand, A. Allou, F. Beauchamp, E. Pluyette, P. Defrasne, and F. Baqué \\ French Alternative Energies and Atomic Energy Commission (CEA), Nuclear Energy Directorate, Cadarache Center, \\ 13108 Saint Paul lez Durance, France
}

Correspondence should be addressed to C. Bertrand; carole.bertrand@cea.fr

Received 29 July 2013; Revised 4 December 2013; Accepted 5 December 2013; Published 9 January 2014

Academic Editor: Mariano Tarantino

Copyright (C) 2014 C. Bertrand et al. This is an open access article distributed under the Creative Commons Attribution License, which permits unrestricted use, distribution, and reproduction in any medium, provided the original work is properly cited.

The MECTUB code was developed to evaluate the risk of swelling and bursting of Steam Generator (SG) tubes. This code deals with the physic of intermediate steam-water leaks into sodium which induce a Sodium-Water Reaction (SWR). It is based on a one-dimensional calculation to describe the thermomechanical behavior of tubes under a high internal pressure and a fast external overheating. The mechanical model of MECTUB is strongly correlated with the kind of the material of the SG tubes. It has been developed and validated by using experiments performed on the alloy 800 . A change to tubes made of Modified 9Cr-1Mo steel requires more knowledge of Modified 9Cr-1Mo steel behavior which influences the bursting time at high temperatures (up to $1200^{\circ} \mathrm{C}$ ). Studies have been initiated to adapt the mechanical model and to qualify it for this material. The first part of this paper focuses on the mechanical law modelling (elasticity, plasticity, and creep) for Modified 9Cr-1Mo steel and on overheating thermal data. In a second part, the results of bursting tests performed on Modified 9Cr-1Mo tubes in the SQUAT facility of CEA are used to validate the mechanical model of MECTUB for the Modified 9Cr-1Mo material.

\section{Introduction and Context}

In the Steam Generator, the heat exchange tubes are the only physical barrier between the secondary sodium and the water. If there is a leakage in the heat exchange tubes, then the water and the sodium are into contact; thus an exothermic chemical reaction occurs between the two reactants. This reaction produces sodium hydroxide and hydrogen.

Overheating of SG tubes can be due to the exothermic reaction. The temperature of the products of the reaction is high and it can reach the vaporization temperature of the sodium hydroxide $\left(1390^{\circ} \mathrm{C}\right.$ under 1 bar). The boiling temperature of the sodium is $880^{\circ} \mathrm{C}$ with a pressure of 1 bar. The heat exchange between the hot reaction products and the neighboring tubes results in a rise of the temperature of these tubes. Then the mechanical characteristics of the heated tubes decrease significantly; this leads the creep phenomenon to become not negligible. Due to the internal pressure of the water/steam, the heat exchange tubes become significantly strained (swelling by a few tens \%). Then the swelled tube may burst in a few tens of seconds, involving large breaks.

This kind of accident can occur if the initial leak has enough time to evolve towards secondary and then a large leak: puncturing of another tube by wastage and propagating to other tubes. This scenario is only possible if the detection is late (the secondary leak intervene before the end of the depressurization of the steam-water in the SG) or if the detection and protection systems fail.

Indeed, it is necessary to remind that the accident in PFR Superheater 2 in 1987 led to the burst of 40 tubes [1]. This accident was able to occur because of the unavailability of the hydrogen detection in sodium. The Sodium-Water Reaction (SWR) was detected very late, by the measurement of the pressure increase in the intermediate loop expansion tank plenum. The secondary loop was protected by the rupture of the bursting discs with triggering of the sodium isolation, depressurization, and draining sequence. 
The PFR accident led to reevaluation of the leak evolution scenario due to a mechanism not taken into account prior to this accident, that is, the bursting of the tubes. Thus this led to revise the safety strategy by taking into account reference accidents involving multiple tube ruptures, instantaneous ruptures, or those occurring over a period of time.

Consequently, a computational program called MECTUB code has been developed to calculate the local effects of the SWR that can induce a secondary leak hazard within the tube bundle [2]. The bursting criteria are linked with strain; this code allows determining the temperature and the strain of target tubes during the SWR event.

The mechanical model of the MECTUB code is strongly correlated with the type of the material of the SG tubes and its intrinsic behavior. It has been so developed and validated with regard to experiments performed on the alloy 800 of the SUPERPHENIX helical tubes SGs [2].

Modified 9Cr-1Mo steel is one of the materials investigated for the SGU tubes of the future sodium-cooled fast reactors (SFRs).

A change to straight tubes made of Modified 9Cr-1Mo induces different result of the heating-bursting time at high temperatures (up to $1200^{\circ} \mathrm{C}$ ); then it requires more in-depth knowledge of Modified 9Cr-1Mo steel behavior. Studies have been initiated to adapt the mechanical model and to qualify it for this material.

The first part of this paper is focused on the description of the mechanical law modelling (elasticity, plasticity, and creep) for Modified 9Cr-1Mo steel and on overheating thermal data.

In the second part, the paper presents elements of the validation of MECTUB mechanical model of the Modified 9Cr-1Mo as the results of bursting tests performed on Modified 9Cr-1Mo tubes in the SQUAT facility of CEA Cadarache Center.

\section{Overheating Tubes Modelling}

2.1. Overheating-Swelling-Bursting Phenomenology. Under normal operating conditions, a tube of SGU can be stressed by effects of internal pressure (up to 200 bar) and by the radial heat flux across the tube (from 20 to $60 \mathrm{~W} / \mathrm{cm}^{2}$ for nominal capacity, according to the exchange zone). Tubes are designed to resist, while the creep of the hottest part remains weak.

When an important SWR occurs, the temperature of reaction products induces a fast local heating (the radial heat flux may exceed $200 \mathrm{~W} / \mathrm{cm}^{2}$ ) to the tube. The internal fluid (steam water) can only remove a small amount of this heat rise.

This kind of forcing will induce strain of material (according to its elasticity, plasticity, and creep characteristics), and the mechanical characteristics of the material drastically fall with the rise of the temperature. Finally, the tube can burst after having swollen under internal pressure action. Figure 1 shows the boundary conditions, initial conditions, and model data.
Considering overheating, thermal conditions, mechanical characteristics of materials, and mechanical laws of the tube, MECTUB thermomechanical code was developed to calculate swelling and bursting local effects which can induce a secondary leak. The code is able to predict the bursting time of the tube and the strain rise during tube swelling phase (wastage effects could also be taken into account).

\subsection{Thermal Boundary Conditions Associated to External} Overheating. The mechanical behaviour laws strongly depend on the temperature. Thus an accurate knowledge of the temperature of the tubes is required. The radial heat conduction equation within the tube is solved to obtain the temperature distribution in the thickness of the tube. Beyond thermal modelling resolution itself, thermal boundary conditions have to be introduced as exactly as possible. The convection between the hot sodium-water reaction products and the target tube wall produces an external overheating flux. In the framework of CEA-ENEA collaboration, this thermal flux has been determined by analysing sodium-water reaction THETRA tests [3] performed in Italy in 1985.

Phases of steady overheating (high temperatures and gradient values) were analysed in order to calculate the overheating flux of the reaction (steady-state calculations). Among all the overheating phases observed during the five THETRA tests, the following conservative values have been selected:

(i) reaction products temperature: $1080^{\circ} \mathrm{C}$,

(ii) heat transfer coefficient between reaction products and tube: $17400 \mathrm{~W} / \mathrm{m}^{2} \cdot \mathrm{K}$.

These values are used for safety calculations as steadystate conditions.

2.3. Mechanical Behaviour and Laws [2]. For each time step the mechanical model uses 3 steps to compute strain and stress. Each step is based on one mechanical property of the material in the following order:

(i) the elasticity, for small and reversible deformation of the material, see details in Section 2.3.1;

(ii) the plasticity effect, to model the irreversible deformation. The plasticity underestimates the elasticity effect (tensile curve lower than the curve of plasticity of the alloy); see details in Section 2.3.2;

(iii) the creep effect induces a relaxation of the stress invariants; see details in Section 2.3.3.

As in the previous literature [2] about MECTUB code, the internal pressure of the tube allows to determine stress and strain components by the use of the balance equation. 


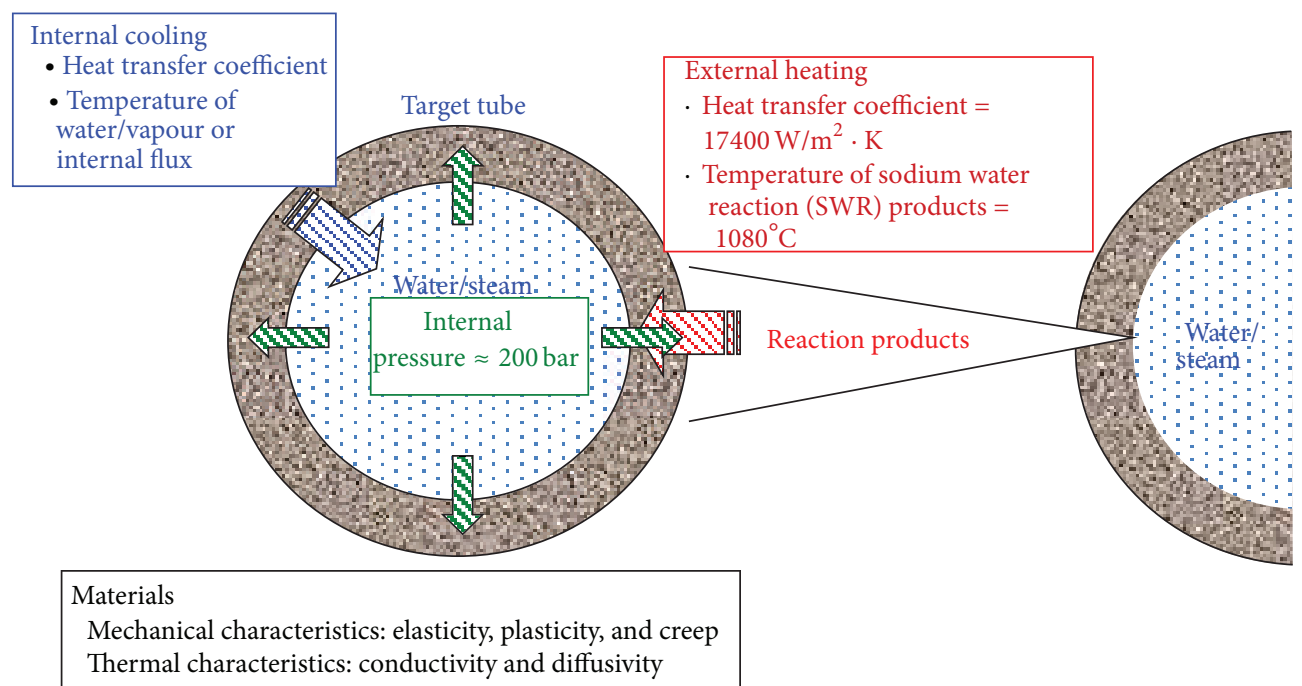

FIGURE 1: Boundary conditions, initial conditions and model data.

The creep part of the equation gives stain variation versus the time. The mechanical algorithm is as follows:

$$
\begin{gathered}
\Delta\left(\sigma_{i}^{t+1}\right)_{\mathrm{el}}=E \Delta \varepsilon_{i}^{t+1}, \\
\Delta\left(\sigma_{i}^{t+1}\right)_{\mathrm{el}+\mathrm{pl}}=\min \left(E \Delta \varepsilon_{i}^{t+1} ; \sigma_{\mathrm{pl}}\left(\varepsilon_{i}^{t}+\Delta \varepsilon_{i}^{t}\right)-\sigma_{i}^{t}\right), \\
\Delta\left(\sigma_{i}^{t+1}\right)_{\text {creep }}=-E A\left(\sigma_{i}^{t}\right)^{n} d t, \\
\Delta\left(\sigma_{i}^{t+1}\right)=\min \left(E \Delta \varepsilon_{i}^{t+1} ; \sigma_{\mathrm{pl}}\left(\varepsilon_{i}^{t}+\Delta \varepsilon_{i}^{t}\right)-\sigma_{i}^{t}\right) \\
-E A\left(\sigma_{i}^{t}\right)^{n} d t
\end{gathered}
$$

where $\mathrm{pl}$ is plasticity and el is elasticity.

Beyond the elasticity and the plasticity laws corresponding to instantaneous deformation of mechanically or thermally loaded structures, it is essential to take into account the creep effects as soon as the temperature becomes very high, even for short time.

2.3.1. Elasticity. For deformations which are not exceeding $0.2 \%$, stresses $(\sigma)$ are proportional to strains $(\varepsilon)$ according to

$$
\Delta \sigma=E \cdot \Delta \varepsilon,
$$

where $E$ is Young's modulus.

RCC-MR rules [4] provide the curve of the variation of Young's modulus of Modified 9Cr-1Mo steal according to temperature (in the range from 45 up to $600^{\circ} \mathrm{C}$ ). Data until $1200^{\circ} \mathrm{C}$ were obtained by a fitting procedure of the parameters of the constitutive model of the Modified 9Cr-1Mo. The data used to fit the parameters of the model were obtained from experimental studies available in [5].

The values of Young's modulus for Modified 9Cr-1Mo steel are given in Table 1.

In Figure 2 it can be seen that for temperatures upper than $700^{\circ} \mathrm{C}$ the drop of the Modified 9Cr-1Mo Young's modulus.

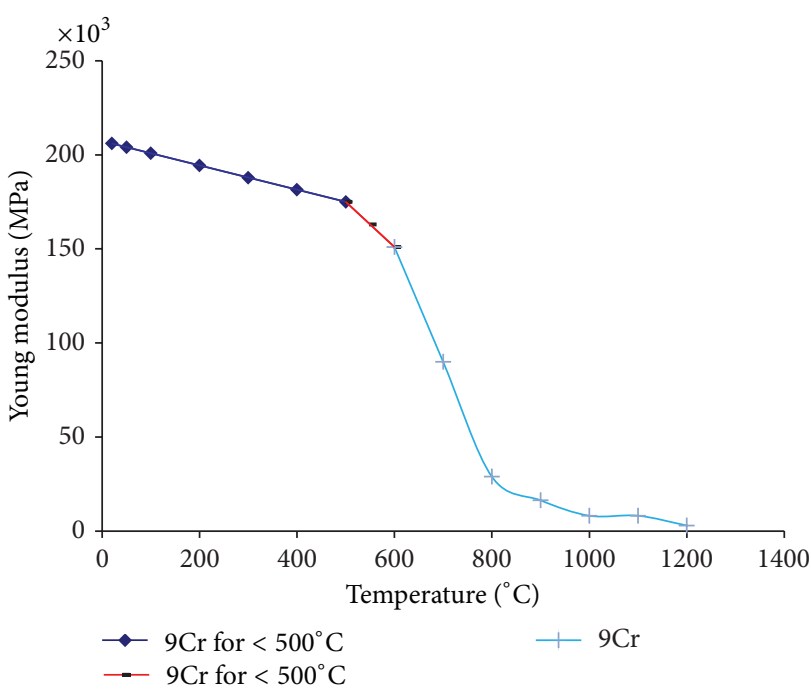

FIGURE 2: Young modulus of $9 \mathrm{Cr}$.

TABLE 1: Values of Young's modulus.

\begin{tabular}{lc}
\hline$T\left({ }^{\circ} \mathrm{C}\right)$ & $E(\mathrm{MPa})$ \\
\hline 600 & 151000 \\
700 & 89944 \\
800 & 28889 \\
900 & 16297 \\
1000 & 8148 \\
1100 & 8148 \\
1200 & 2963 \\
\hline
\end{tabular}

2.3.2. Plasticity. For greater strains, there is no linear variation between strain and stress. On the basis of dynamic tensile tests at $600^{\circ} \mathrm{C}$, the plastics curves are known. The results are 


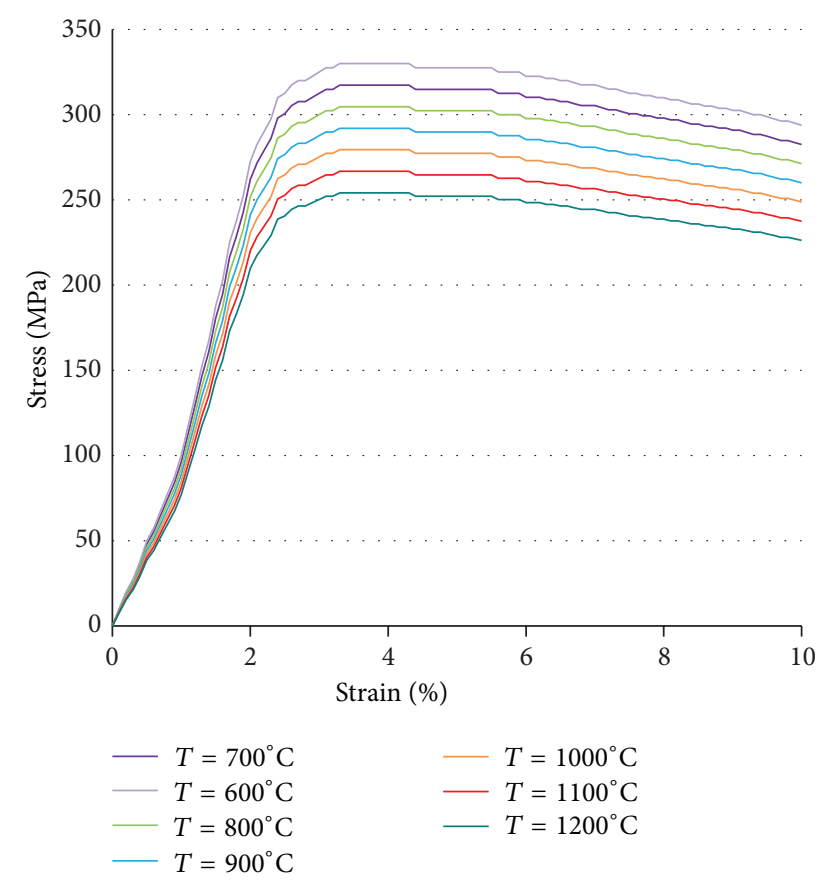

FIGURE 3: Plasticity curves of 9Cr-MECTUB model.

obtained from a traction test performed with a strain rate of $0.42 \% / \mathrm{s}[6]$.

With the hypothesis that the curve $\left(600^{\circ} \mathrm{C}\right)$ is the reference plasticity curve (Figure 3 ), the other temperature plastic curves are deduced, using the following empirical formula:

$$
\sigma\left(T>600^{\circ} \mathrm{C}\right)=\sigma\left(T=600^{\circ} \mathrm{C}\right) \times \frac{E\left(T>600^{\circ} \mathrm{C}\right)}{E\left(T=600^{\circ} \mathrm{C}\right)} .
$$

For strain values exceeding $10 \%$, it is assumed that the tube material is perfectly plastic: the strain increases at constant stress.

2.3.3. Creep. It was clearly shown that during permanent conditions tests, a significant increase of the tube strain could be observed up to rupture. Then the time variation of the strain is taken into account by the mean of the creep term of the motion equation.

Three successive phases have to be considered to give an analytical description of the creep: primary creep (strain rate decreases with time), secondary creep (strain rate increases linearly with time), and tertiary creep (strain rate increases with time up to rupture).

Since creep laws could not be established for 9Cr over a wide field (of strain, stress, and temperature), it was decided to solve this problem, using only a simplified secondary creep law (Norton's law), where strain rate increases linearly with respect to time [7]:

$$
\frac{d \varepsilon_{\text {creep }}}{d t}=A \sigma^{n}
$$

where $t$ represents time variable.

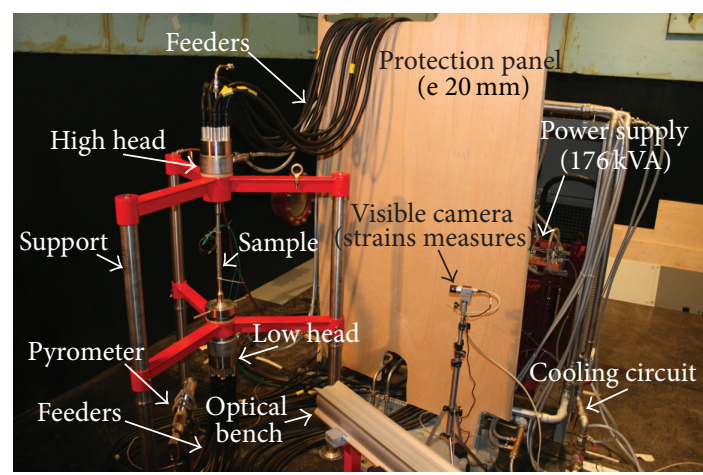

FIgURE 4: SQUAT test facility.

TABLE 2: Norton law coefficients of MECTUB model.

\begin{tabular}{lccccccc}
\hline Temperature $\left({ }^{\circ} \mathrm{C}\right)$ & 600 & 700 & 800 & 900 & 1000 & 1100 & 1200 \\
\hline$n$ & 19.60 & 3.03 & 6.55 & 18.34 & 7.25 & 3.63 & 3.15 \\
$-\log A$ & 51.77 & 10.77 & 15.77 & 38.08 & 14.62 & 7.68 & 6.19 \\
\hline
\end{tabular}

$A$ and $n$ represent constant coefficients which depend only on the temperature.

Norton's law coefficients ( $A$ and $n$ ) are determined on the basis of tensile curve [6]. Their values are given in Table 2.

\section{Bursting Tests of Modified 9Cr-1Mo Tubes}

The aim of the tests is to heat as fast as possible a pressurized tube until it reaches a constant temperature. Sample tubes are all identical and representative of the reality (such as dimensions and materials). Input data are the temperature and the internal pressure. The main output data are the bursting time, the temperatures, the pressure, and the strain versus time. Results are injected in the model to validate the code, by comparing, for example, bursting time calculated and bursting time measured.

3.1. SQUAT Test Facility. In order to validate the mechanical model of the Modified 9Cr-1Mo, bursting tests of SG tubes have been performed in the SQUAT facility. The experimental results will be compared with the calculations.

The experimental device SQUAT is shown in Figure 4. It includes a heating unit, a mechanical group including a support, and top and bottom heads on which the tube sample is welded, as well as a data acquisition system which is constituted by measuring instruments and by computing means. Heating of the sample tube is performed by Joule effect.

3.2. Measuring Instruments. A pyrometer is used in order to measure the temperature. An imaging device and a telemetry laser are used in order to measure the strain.

A pyrometer (Keller, Cellatemp PL22 AF3) is selected in order to measure the temperature at the surface of the tube. This device works within the range of $1-1.7 \mu \mathrm{m}$ (the manufacturer recommends a target temperature failing in the range from 250 to $1600^{\circ} \mathrm{C}$ ). 
A laser distance sensor (BAUMER OADM20I4440) is used for the strain measurement. This device works within the range of 30-50 $\mathrm{mm}$ with an accuracy of $0.01 \mathrm{~mm}$.

Furthermore the internal pressure of the tubes is measured.

The high-pressure gas circuit is fed by tanks situated outside the tests hall. A sensor of pressure "SWAGELOK 0250 bar S model trans" is used to recover the level of internal pressure of the sample.

3.3. Acquisitions Systems and Control System. The control system consists in a module integral PXI-1050:

(i) a processor,

(ii) a record (disk) of storage of the data,

(iii) a card of acquisition (PXI-6259) connected with various modules of input-output:

(a) SCXI-1303 for the temperatures measurement (ambient temperature, temperature of the power cable),

(b) SCXI-1161 for the flow, pressure, position, temperature obtained by pyrometer measurement,

(c) SCB-68 for the analog exit of heating instruction, the commands output, and the input (defects, safety, thresholds).

This control system is managed by a program "LabVIEW on 2011." After a phase of initialization, 2 independent buckles are used:

(i) a buckle is used for the acquisition of the measurements and their recording (a period of $120 \mathrm{~ms}$ ),

(ii) a second buckle does the command and controlsystem part and interfaces human machine (cadence of $100 \mathrm{~ms})$.

3.4. Data Exploitation. The data obtained from the system LabVIEW are processed by using Excel. The excel file presents the main measures:

(i) the temperature of the middle of the tube is measured by the pyrometer,

(ii) the sample pressure and the tube extension,

(iii) the output voltage of the power supply transformer.

3.5. Test Procedure. The duration of tests does not exceed half an hour. The setup phase consists in preheating and pressurizing the sample tube. In the end of this phase, the sample tube is heated to a nominal temperature with a controlled heating rate of approximately $100^{\circ} \mathrm{C} / \mathrm{s}$ until the bursting of the tube. The procedure of a test is presented Figure 5.

3.6. Tests Parameters and Mains Results. The tested tubes are made with Modified 9Cr-1Mo steel. Their length is $330 \mathrm{~mm}$. The external diameter is of $16.4 \mathrm{~mm}$ and the thickness is equal

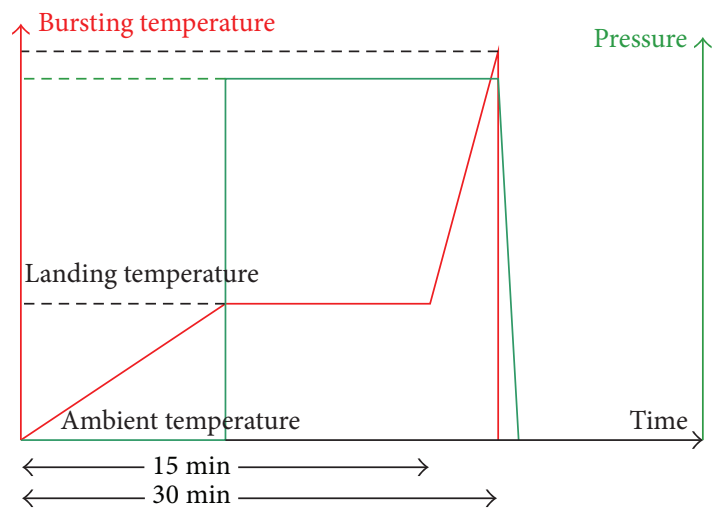

Figure 5: Principle of a bursting test.

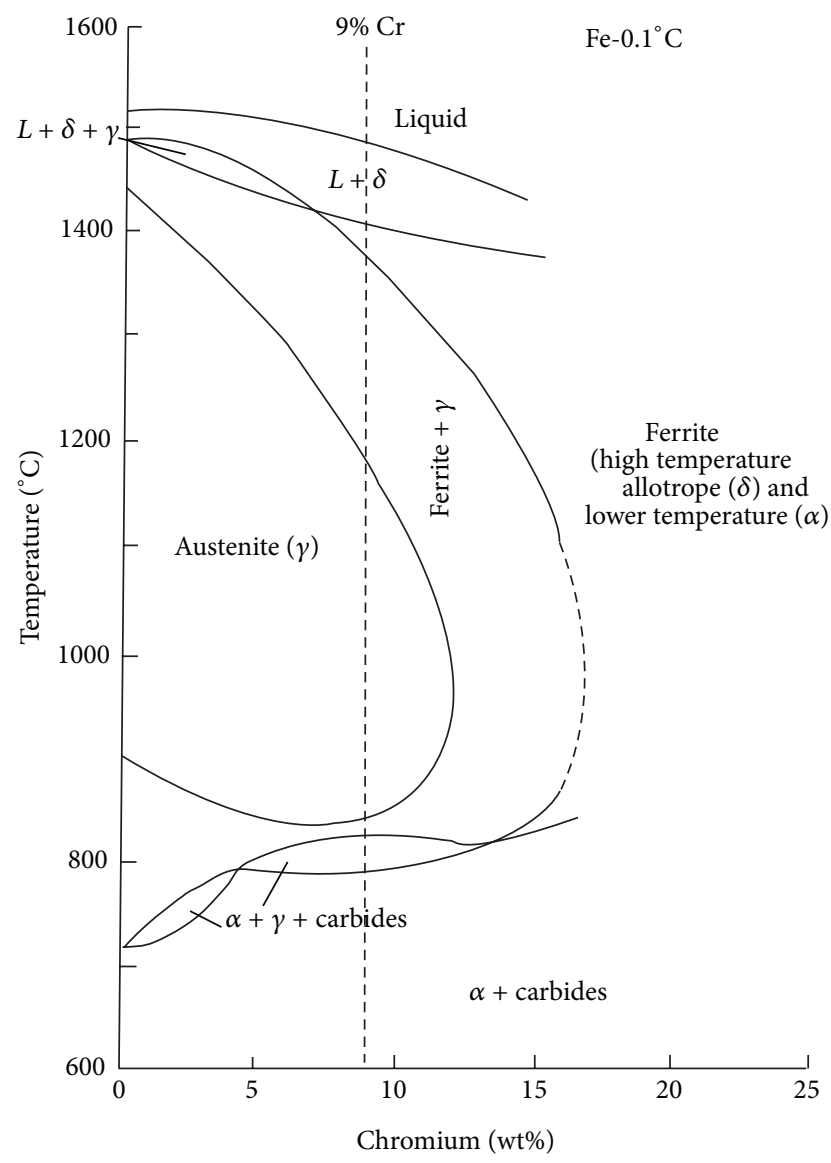

FIgure 6: Modified 9Cr-1Mo phase diagram.

to $2.2 \mathrm{~mm}$. Ten tests were performed. The parameters of the tests are shown in Table 3 as well as the main results.

Each test starts in Martensitic phase with a temperature of $300^{\circ} \mathrm{C}$. For each test performed at a target temperature upper than $825^{\circ} \mathrm{C}$, a phase change occurs during the test. Temperature phase change limits can be seen in Figure 6 .

The difference of $11 \mathrm{~s}$ between SQUAT9 and SQUAT10 tests (performed with the same instructions of temperature 
TABLE 3: Experimental results of SQUAT tests.

\begin{tabular}{|c|c|c|c|c|c|}
\hline SQUAT test & Pressure (bar) & Target temperature $\left({ }^{\circ} \mathrm{C}\right)$ & Bursting time measured (s) & Breaking elongation (\%) & Strain rate $(\% / s)$ \\
\hline 9 & 70 & 1050 & 390 & 23 & 0.06 \\
\hline 10 & 70 & 1050 & 401 & 15 & 0.04 \\
\hline 7 & 70 & 1100 & 187 & 18 & 0.10 \\
\hline 8 & 70 & 1200 & 42 & 20 & 0.48 \\
\hline 1 & 70 & 1280 & 10.2 & 3 & 0.29 \\
\hline 2 & 170 & 850 & $>2150$ & - & - \\
\hline 3 & 170 & 900 & 460 & 35 & 0.08 \\
\hline 4 & 170 & 950 & 111 & 26 & 0.23 \\
\hline 5 & 170 & 1000 & 39 & 20 & 0.51 \\
\hline 6 & 170 & 1050 & 19.5 & 12 & 0.62 \\
\hline
\end{tabular}

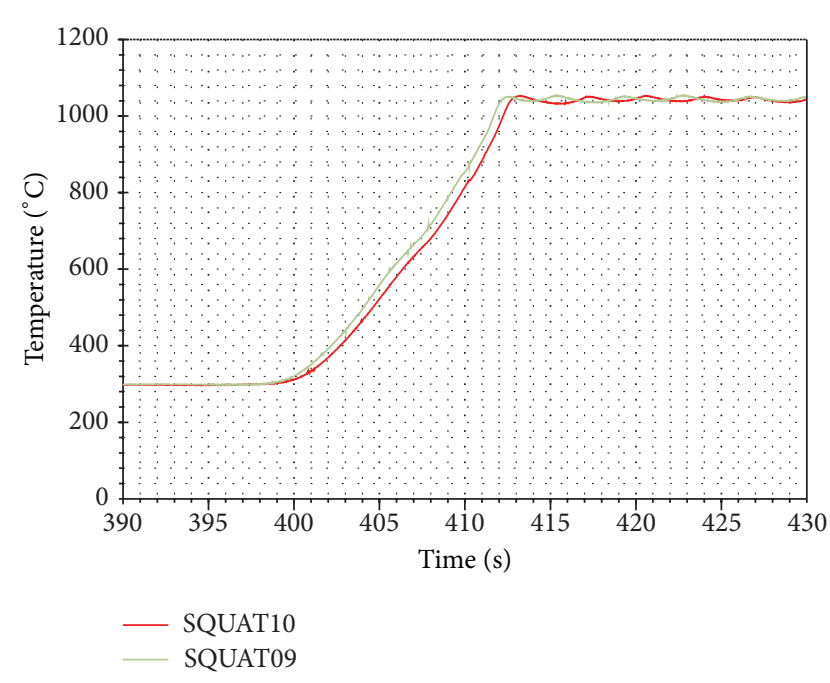

FIGURE 7: SQUAT09 and SQUAT10 temperatures operating conditions.

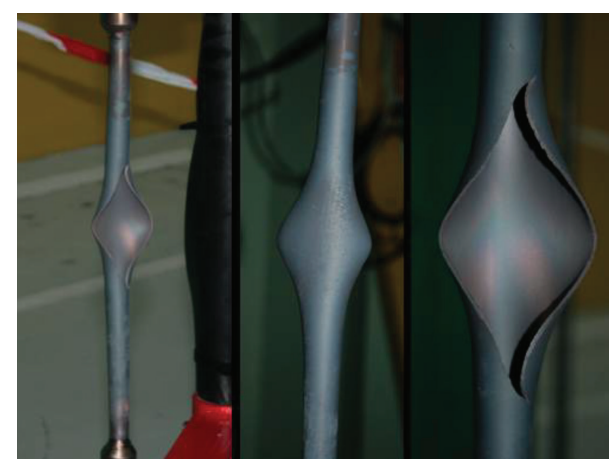

FIGURE 8: View of the tube after the SQUAT 3 test.

and pressure) is mainly due to the differences on the temperature values obtained between these 2 tests (the operating conditions could be not exactly the same, see Figure 7). On the basis of these 2 tests, we can claim that at least there is an uncertainty of $\pm 11 \mathrm{~s}$ on the measured bursting time for a given target temperature.

Figure 8 shows the sample number 3 after bursting.

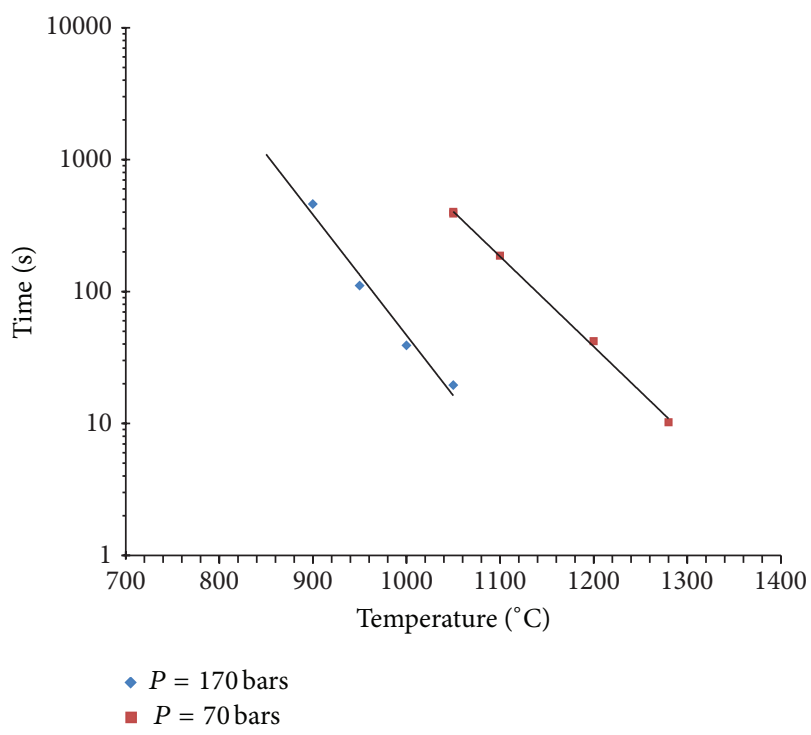

Figure 9: Bursting time of the tests according to the target temperature.

Figure 9 shows the evolution of the bursting time according to the target temperature for a given pressure. In the semilog space, the bursting time decreases linearly with the increase of the temperature.

\section{Results and Discussion}

For every SQUAT experiment, Table 4 gives rupture times obtained experimentally and from calculation with MECTUB code. The comparison shows a good agreement between calculations and experiments. This good agreement is probably due to the fact that the measured temperature time series are imposed as input temperature data to the code.

In order to estimate the influence of the uncertainties of measurement in these computation, the calculations (shown in Table 3) are performed again, by using the lower and the upper bounds of the range of the SQUAT measurements (pressure $\pm 0.5 \%$ /temperature $\pm 0.5 \%$ ). Considering that the discrepancies on the computed bursting time induced by 
TABLE 4: Comparison of rupture time of the $9 \% \mathrm{Cr}$ with the experimental measures SQUAT.

\begin{tabular}{|c|c|c|c|c|c|}
\hline $\begin{array}{l}\text { SQUAT } \\
\text { test }\end{array}$ & $\begin{array}{l}\text { Target pressure } \\
\text { (bar) }\end{array}$ & $\begin{array}{c}\text { Target temperature } \\
\left({ }^{\circ} \mathrm{C}\right)\end{array}$ & $\begin{array}{l}\text { Bursting time } \\
\text { measured (s) }\end{array}$ & $\begin{array}{l}\text { Bursting time } \\
\text { calculated (s) } \\
\text { MECTUB v2.0 }\end{array}$ & $\begin{array}{c}\text { Relative error } \\
(\%)\end{array}$ \\
\hline 1 & 70 & 1280 & 10.2 & 13.8 & 26.1 \\
\hline 2 & 170 & 850 & $>2150$ & $>2500$ & 0 \\
\hline 3 & 170 & 900 & 460 & 458 & -0.4 \\
\hline 4 & 170 & 950 & 111 & 97 & -14.4 \\
\hline 5 & 170 & 1000 & 39 & 38 & $-2,6$ \\
\hline 6 & 170 & 1050 & 19.5 & 20 & 0 \\
\hline 7 & 70 & 1100 & 187 & 141 & -32.6 \\
\hline 8 & 70 & 1200 & 42 & 29 & -44.8 \\
\hline 9 & 70 & 1050 & 390 & 337 & -15.7 \\
\hline 10 & 70 & 1050 & 401 & 349 & -14.9 \\
\hline
\end{tabular}

TABLE 5: Sensibility calculations on the SQUAT tests pressure and the temperature.

\begin{tabular}{lccccc}
\hline SQUAT test & Nominal $P, T$ & $T+0.5 \%$ & $T-0.5 \%$ & $P+0.5 \%$ & 13.8 \\
1 & 13.8 & 12.7 & 14.6 & No rupture & 458 \\
3 & 458 & No rupture & 221 & 89 & 13.8 \\
4 & 97 & 58 & 40 & 38 & $10.5 \%$ \\
5 & 38 & 38 & 21.5 & 19.3 & 141 \\
6 & 19.5 & 19.4 & 141 & 29 & 19.5 \\
7 & 141 & 141 & 32.2 & 38 \\
8 & 29 & 21.3 & 337 & 337 \\
9 & 337 & 337 & 348.4 & 348.5 \\
10 & 349 & 351 & & 348.5 \\
\hline
\end{tabular}

the measurement uncertainty could be estimated. Table 5 gives results of these computations.

Effect of pressure variation $( \pm 0.5 \%)$ on the rupture time is negligible $(0.5 \mathrm{~s})$, except for SQUAT4 test for which the rupture time is decreased in 8 seconds for pressure increase of $0.5 \%$.

The uncertainty of the temperature measurements $( \pm 0.5 \%)$ shows no or few variations of rupture times for 6 tests over 9 ( 2 seconds at maximum). The decrease of SQUAT8 time to bursting is more important when the upper boundary of temperature is applied ( -8 seconds). The SQUAT4 calculation gives significant differences, as well as SQUAT3 for which the criteria of rupture are not any more affected.

In the code the change of phase is taken into account by the changes in the material mechanical properties. Norton's law coefficients ( $A$ and $n$, given in Table 2 ) are determined by the use of some tensile curves [6]. The results of the tests SQUAT3 and SQUAT4 show that mechanical properties implemented into the code are not accurately fitted for a temperature of $950^{\circ} \mathrm{C}$. Our mechanical model suffers from a lack of data in this temperature range.

Except for SQUAT10 test, it is noticed that rupture time vary in a logical way when the lower boundaries are applied: a decrease in the pressure or the temperature tends to delay the bursting. The opposite comes true for the pressure: an increase tends to reduce the time to break. Furthermore, the time to break tends to decrease for an increase $(0.5 \%)$ of the temperature.

Concerning SQUAT10 case, the computed bursting time differences remain lower than $0.6 \%$.

\section{Conclusions}

The MECTUB code has been developed in order to model the thermomechanical behaviour of pressurized tubes under overheating load. This code has been set up and validated using experiments performed on the alloy 800 of the SUPERPHENIX helical tubes SGs.

A new test bench was set up and qualified to burst heated tubes. The time to burst was successfully detected using the internal pressure measurements. The results obtained with this test bench highlight a logarithmic trend in the decrease of the bursting time versus the increase of the overheating temperature for a given internal pressure.

The experimental studies shown in this paper allowed us to adapt the mechanical model and to qualify it for Modified 9Cr-1Mo material.

Mechanical modelling takes into account the elastic, plastic, and creep effects up to high temperature $\left(1200^{\circ} \mathrm{C}\right)$. The creep law has been reduced to a simpler Norton's law.

On the basis of bursting tests on the Modified 9Cr1 Mo steel, it appears that the MECTUB code is able to be 
conservative in the estimate of the rupture time. Then it could be used for safety analysis of SG of SFRs.

\section{Nomenclature}

MECTUB: Modélisation d'EClatement de Tubes

(model of tubes bursting)

PFR: $\quad$ Prototype Fast Reactor

SFR: $\quad$ Sodium-Cooled Fast Reactor

SG: $\quad$ Steam Generator

SGU: $\quad$ Steam Generator Unit

SQUAT: Section of Qualification of the Accidental codes for Tubes heat exchangers

SWR: $\quad$ Sodium-Water Reaction

THETRA: THErmal TRAnsfer

$A, n: \quad$ Norton's law coefficients

$E$ : Young's modulus

$\sigma: \quad$ Stress

$\varepsilon: \quad$ Strain

T: $\quad$ Temperature

el: $\quad$ Elasticity

pl: $\quad$ Plasticity.

\section{Conflict of Interests}

The authors declare that there is no conflict of interests regarding the publication of this paper.

\section{Acknowledgment}

The authors would like to express their thanks to EDF and AREVA for their financial support.

\section{References}

[1] A. M. Judd and R. Currie, "The under-sodium leak in PFR superheater 2, February 1987," Nuclear Technology, vol. 31, no. 3, pp. 221-230, 1992.

[2] F. Baqué, "A thermomechanical model for overheating studies of LMFBR steam generator tubes during a sodium/water reaction," in Proceedings of the IAEA Specialists' Meeting on Steam Generator Failure and Failure Propagation Experience, Aix-enProvence, France, September 1990.

[3] F. Baqué, P. Martin, P. Agostini, and L. Lorenzelli, “Thermal characterization of sodium-water reaction: the THETRA program," in Proceedings of the International BNES Conference, Paper 590, pp. 485-489, British Nuclear Energy Society, Guernsey, UK, May 1986.

[4] "RCC-MR," Règles de conception et de construction des matériels mécaniques des îlots nucléaires RNR.

[5] G. Roux, Prévision des contraintes résiduelles induites par le soudage TIG dun acier martensitique (X10CrMoVNb9-1) [Ph.D. thesis], Pierre et Marie Curie University, Paris, France, 2007.

[6] A. Bougault, C. Janis, and J. C. Brachet, "Experimental description of the mechanical behavior of $9 \mathrm{Cr}$ up to $1200^{\circ} \mathrm{C}$ to anticipate the behavior of material during welding and manufacturing of thick plates or accidental conditions," Meeting on weldability of modified 9Cr1Mo, CEA unpublished data, 2003.

[7] F. H. Norton, Creep of Steel at High Temperatures, Mc Graw-Hill, 1929. 


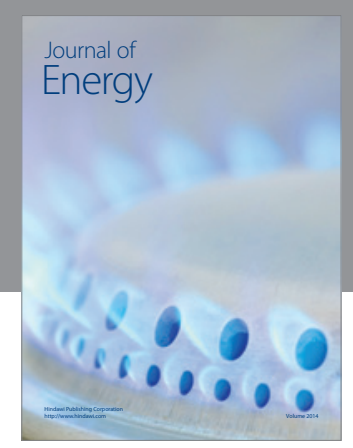

Journal of

Industrial Engineering
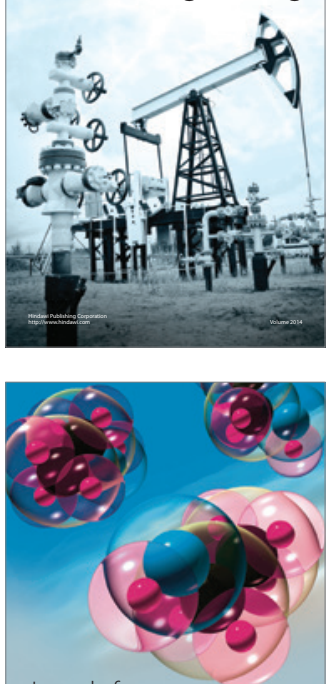

Fuels
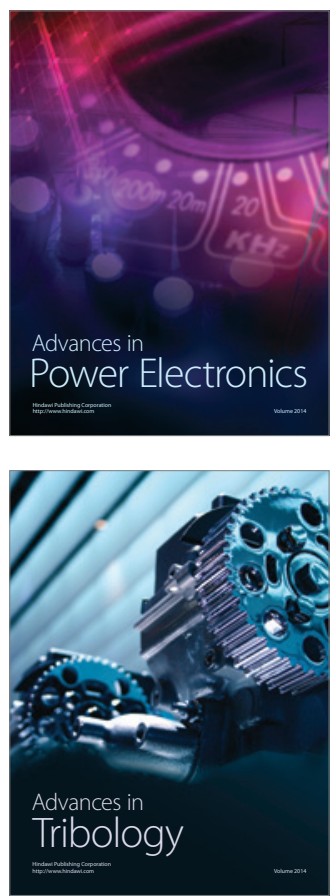

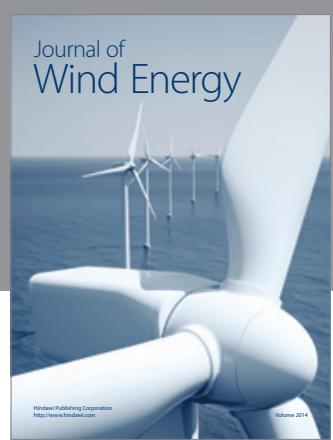

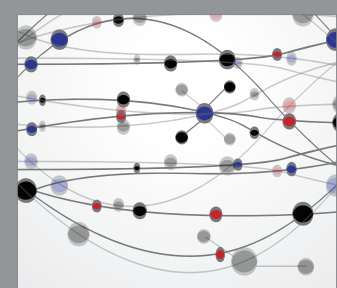

The Scientific World Journal

Submit your manuscripts at http://www.hindawi.com

Journal of

Structures
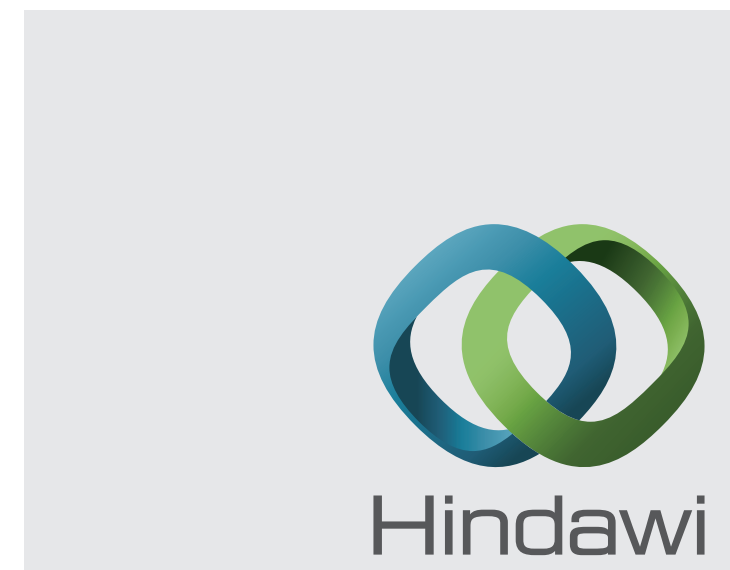

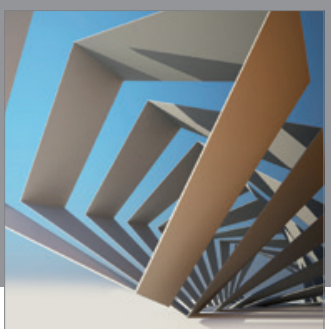

Rotating

Machinery
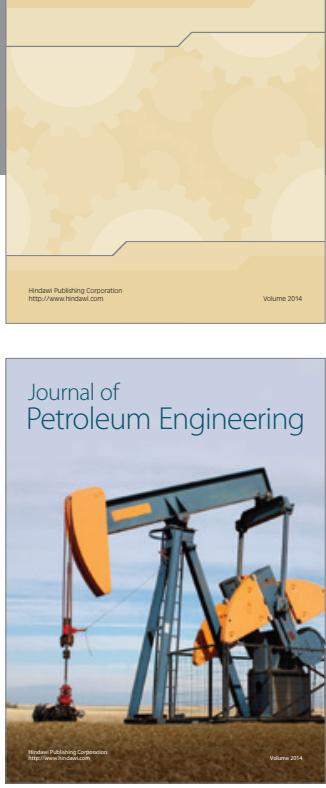

Journal of

Solar Energy
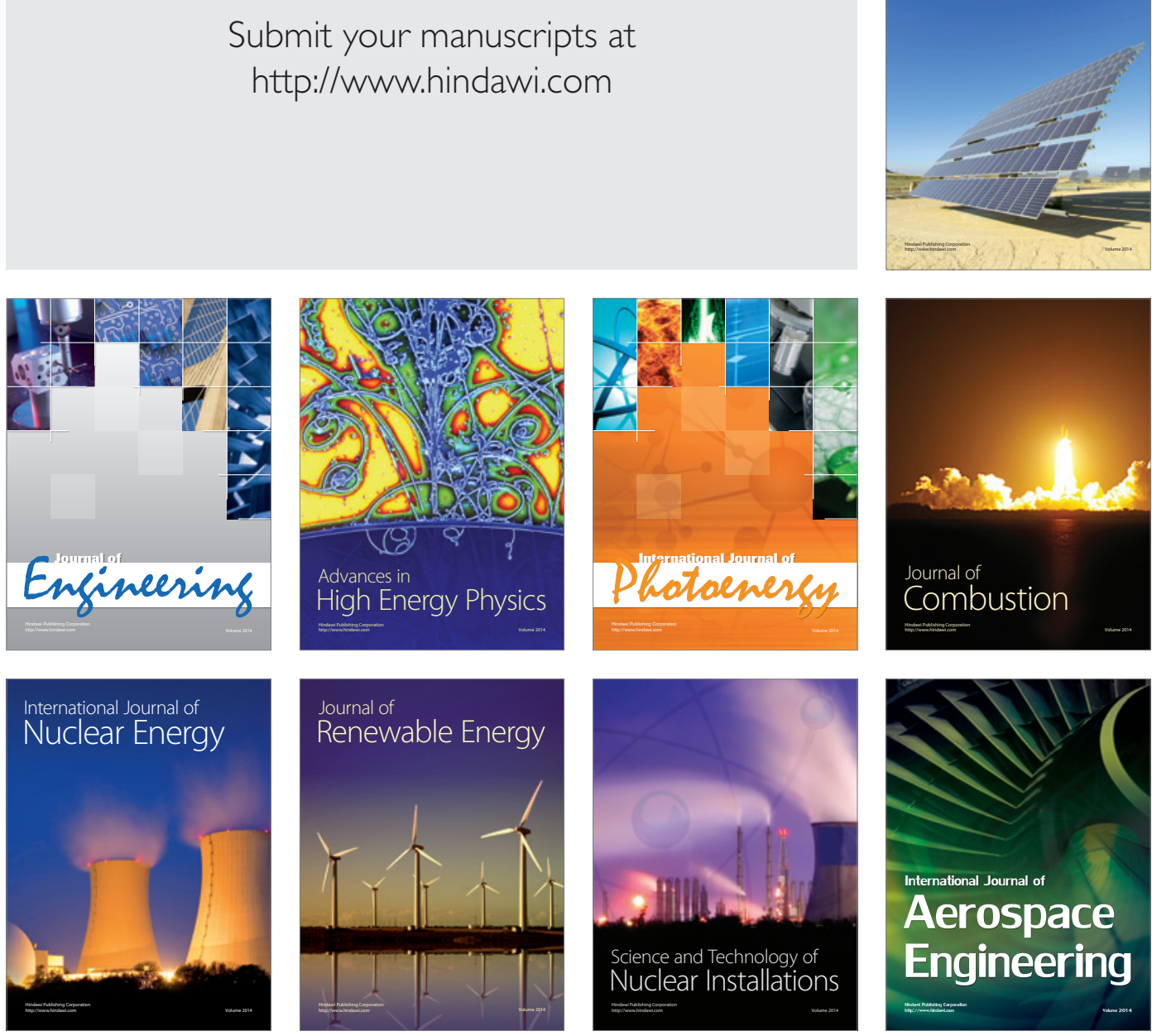